\section{Thinking in Different Directions}

\author{
M. Castillo, Editor-in-Chief
}

A few days ago, we were having our weekly case conference and we saw a patient with an interesting intracranial lesion. I asked a resident to look at the clinical record and find out what the discharge diagnosis was. He then proceeded to inform me that it was a meningioma. "How do they know if they have not biopsied it?" I asked. After much searching, our trainee found out that the neurosurgeons had used our initial impression as the final diagnosis, and slowly we had all begun to assume that this was indeed the confirmed diagnosis and kept quoting it on our own reports. This is an example of thinking that begins and ends with an assumption (often wrong), also known as circular or paradoxical thinking and in logic called a "logical fallacy." It is my impression that in imaging and in medicine in general, we spend a considerable amount of time engaged in this type of reasoning and that this process is more common now than in the past, perhaps because of the repetition ("cutting and pasting") that is found in patient medical records. In circular thinking, a conclusion cannot be proved false or true if it arose from a false premise. Because repeating a statement in circular fashion seems to make it stronger, circular thinking ends by creating statements that sound true and gain wide support (thus, the above-mentioned patient now carries a diagnosis of "meningioma"). There is no doubt that circular thinking is dangerous and that we must do our best to avoid it.

The opposite of circular thinking is linear (vertical) thinking. In this type of reasoning, progress is made in a step-by-step fashion and a response to each step must exist before advancing to the next one. Although linear thinking advances by logic, it is by its own nature highly focused on single pathways and as such tends to ignore other possibilities and alternatives. Linear thinking is basically a binary process in which answers are "Yes" or "No" (correct or incorrect), excluding all considerations beyond these 2 responses. These features make it fast, organized, and sequential and therefore it is the most common type of thought process used. ${ }^{2}$ People generally regard linear thinking as an honest, mature, and intelligent process when in reality it lacks ingenuity, innovation, and originality. Similar to circular thinking, linear thinking is characterized by repetition and is, in the long term, detrimental to intellectual advancement.

Where linear thinking is a "safe" process, a third type of reasoning called lateral (horizontal) thinking is risky, uneven, adventurous, more difficult, and not widely accepted. Lateral thinking views a problem from multiple perspectives, many of them random. Because lateral thinking is based on discovery and exploration of spontaneous events, it is the opposite of linear thinking: slow, disorganized, and nonsequential. Lateral thinking teeters close to the edge of disaster because it is greatly affected by luck

http://dx.doi.org/10.3174/ajnr.A3647 and chance and may easily turn into chaos. Most individuals are not organized enough to use it and rapidly become overwhelmed by the choices it offers. The brightest individuals know when to use vertical and lateral thinking and avoid circular reasoning. In popular culture, linear thinking is linked to men while lateral thinking is linked to women.

Howard E. Gardner, a world-famous professor of cognition and education at Harvard University, formulated the concept of multiple intelligences. ${ }^{3}$ We humans have different ways of learning and processing information and thus we are different and independent from each other. Although those who favor this concept oppose the idea of a "general intelligence factor," it is likely that all individuals share both, that is, they are smart as individuals but also share a collective intelligence that makes them similar to all other human beings. Dr. Gardner has separated intelligence into the following categories: linguistic, logical-mathematical, musical, spatial, bodily/kinesthesic, interpersonal, intrapersonal, naturalistic, and possibly existential (after much thinking I have come to the conclusion that there must be others because I believe I do not possess any of these!). However, I agree with him when he states that education (not only in America but worldwide) is based mostly on logical (mathematics) and linguistic (language arts) intelligence and that current methods for assessing intelligence (such as IQ tests) measure only these 2 features. This brings up the inadequacy of the current schooling systems that disregard other types of intelligence. Most current education (and research) depends on mainly linear thinking.

A fascinating endeavor that encourages folks to express their different intelligences and to think laterally is TED.com (TED stands for: technology, entertainment, design). This nonprofit organization that was started in 1984 contains more than 1400 (as of this writing) varied and exciting conferences by some of the world's smartest and most diverse and laterally thinking individuals. For a fantastic account of how it works, I suggest reading Nathan Heller's article in The New Yorker titled "List and Learn." The most viewed TED conference (more than 15 million times) is one given by British education specialist Sir Ken Robinson in 2006 (a newer one was posted in May 2010 and has been viewed nearly 4 million times). ${ }^{5}$ Robinson argues that university professors educate students to become, well... university professors in a process so linear that it kills all creativity and discourages many students from exploring alternative avenues. He also calls attention to the ever-diminishing value of education degrees (and those of us who live in university towns know that sometimes all that a $\mathrm{PhD}$ gets you is a better waitressing job). The rigidity of school systems that are based on mathematics and linguistics results in linear thinking stifling the creativity associated with lateral thinking and is thus harmful to society.

In an article in The New York Times, ${ }^{6}$ Andrew Hacker explains why more than one-third of high school students fail algebra and states that difficulty with mathematics may be responsible for up to $45 \%$ of high school dropouts in the United States. Aptitude 
tests such as the American SAT (Scholastic Aptitude Test) and the ACT (American College Testing) concentrate in measuring 2 subjects: mathematics and linguistics (the pillars of linear thinking, as stated previously). Mr. Hacker proposes that perhaps just basic algebra and what he astutely calls "citizen statistics" may be enough for most us, whereas more advanced courses such as calculus should be reserved for fewer, gifted individuals who seek careers that depend on the understanding of higher mathematics. As Sir Ken Robinson states, "We are educating people out of their creative capacities."

Does studying liberal arts and the humanities make us better physicians? I believe it does. I have been unable to notice any differences with respect to knowledge of biologic sciences in our daily work between residents who come from a "hard" science background and those with a liberal arts education, and I find that personally I like the latter better. Medical schools are aware of this, and some such as Boston University and Brown University encourage this type of liberal arts curriculum and reserve a number of places in their medical schools for these individuals. More than $40 \%$ of medical students at the University of Pennsylvania come from non-premed backgrounds. ${ }^{7}$ The liberal arts may also be useful to medical students, and the Mount Sinai School of Medicine in New York has a specific humanities and medicine program. The separation of liberal arts from sciences is, in my opinion, damaging and ends up suppressing the human qualities of many excellent and caring young individuals. Because liberal arts are characterized by lateral thinking, bringing these individuals into our world of linear thinking will prove to be beneficial for all.

I am not aware of imaging methods having been used to study these different types of thinking. There are, however, several principles that control all human thought processes. ${ }^{8} \mathrm{~A}$ basic principle of thinking is that it is the product of concurrent brain activity in multiple regions that together form a large-scale cortical network. This is a type of functional connectivity that has been documented in thousands of fMRI reports. Also, each cortical region can perform multiple functions, and these same functions can also be performed by different regions, an observation that may explain thought (and function) plasticity. Rather than a strict linear or vertical organization, the brain prefers a lateral or horizontal organization that serves as its own backup and redundant system. Unfortunately, each cortical region can only do so much and thus has a limited capacity. Conversely, these constraints force other parts of the brain to collaborate, and this helps it adapt to many situations. The topologies of large-scale networks are in constant flux, adapting themselves to the demands of tasks. The brain is not dumb: it uses the minimum amount of resources needed for each activity, but, if one network becomes insufficient, additional ones are immediately recruited. The brain's topology has 2 components: membership and connectivity, and both are in constant flux. Just as the Internet does, the brain also has a limited bandwidth, resulting in a finite amount of resources that it can use. This bandwidth, up to a certain extent, varies from individual to individual and thus some are more successful in multitasking than others. Increased brain bandwidth seems to be connected to lateral thinking.

Lateral thinking is important and is not used sufficiently in the sciences, but this is beginning to change. Of course, we radiolo- gists can take it to a silly extreme, as seen in a recent advertisement that intended to recruit a lateral-thinking technologist for a vertical MR imaging (upright) scanner! ${ }^{9}$ Radiologists actually think dimensionally, and 2D and 3D processes play an important role in the interpretation of images in which it all begins as the former and ends as the latter. I like to think of this as a process that also begins vertically and then branches horizontally. Some of our trainees have more trouble making this transition and thus take longer to learn the specialty. It is possible that some may survive and graduate not being able to think 3-dimensionally, but they will never survive if they think circularly.

\section{REFERENCES}

1. Circular reasoning. http://en.wikipedia.org/wiki/Circular_ reasoning. Accessed on May 2, 2013

2. Is linear thinking bad? http://www.andyeklund.com/creativestreak/ 2012/06/is-linear-thinking-bad.html. Accessed on May 2, 2013

3. http://www.howardgardner.com. Accessed on May 2, 2013

4. Heller N. List and Learn. The New Yorker, July 9, 2012

5. http://www.ted.com/talks/ken_robinson_says_schools_kill_creativity. html. Accessed on May 2, 2013

6. Hacker A. Is algebra necessary? The New York Times, July 28, 2012. http://www.nytimes.com/2012/07/29/opinion/sunday/is-algebranecessary.html. Accessed on May 2, 2013

7. Kliff S. Why medical schools like to accept STS majors. Newsweek, September 10, 2007

8. Just MA, Varma S. The organization of thinking: what functional brain imaging reveals about the neuroarchitecture of complex cognition. Cogn Affect Behav Neurosci 2007;7:153-91

9. http://www.radmagazine.co.uk/JobPDFs/441115.pdf. Accessed on May 2, 2013

\section{EDITORIAL}

\section{Acute Stroke Intervention Results: The "Denominator" Fallacy}

\author{
M. Goyal
}

$\mathrm{t}$ is common these days to have conversations at meetings related to outcome of endovascular procedures for acute stroke. Very often, interventionalists can be seen stating proudly how their good outcome rate ( $\mathrm{mRS}<2$ ) is $>60 \%$, or much higher than the other center in their city, or higher than the various trials in the literature. Of course, their basis of calculation for their good outcome rate uses the total number of stroke cases that underwent intra-arterial (IA) therapy at their center. Very often, the numerator and the denominator are limited to anterior circulation strokes. This process takes a further leap forward when devices or imaging paradigms (for acute stroke treatment) are being compared. Various recent studies such as IMS III, ${ }^{1}$ SYNTHESIS, ${ }^{2}$ MRRESCUE, ${ }^{3}$ TREVO $2,{ }^{4}$ SWIFT, ${ }^{5}$ and STAR ${ }^{6}$ have different good outcome rates. Speakers at meetings, discussions in hallways, and vendor sales pitches have a tendency to use these good outcome rates without necessarily paying enough attention to the denominator. What kind of patients received IA therapy? What were the precise selection criteria? Did every patient who fulfilled those

http://dx.doi.org/10.3174/ajnr.A3770 